Fecha de recepción: junio 2020

Fecha de aceptación: agosto 2020

Versión final: septiembre 2020

\section{O Assentamento Rural Horto Aimorés e a Extensão Universitária do Projeto Bambu: um estudo de caso}

Gabriel Fernandes dos Santos ${ }^{(1)}$, Silvia Sasaoka ${ }^{(2)}$ y Marco Antonio dos Reis Pereira ${ }^{(3)}$

Resumo: Um assentamento rural representa a etapa de conquista na luta pela posse de uma terra e resulta de esforços coletivos de um movimento social. Ainda assim, seus moradores encontram diversas dificuldades à sua estruturação e permanecem em vulnerabilidade social, devido a desigualdade de acesso aos direitos de cidadania. Neste contexto, foi estabelecida a parceria entre moradores do assentamento rural Horto de Aimorés em Bauru e a extensão universitária do Projeto Bambu. No mesmo período formou-se a Associação Agroecológica Viverde com o apoio do grupo Taquara composto por alunos das faculdades de Design, Arquitetura e Engenharia da UNESP, campus de Bauru. As atividades extensionistas com base no design social permitiram a profissionalização dos assentados como artesãos de bambu. Com foco na geração de renda, realizou-se oficinas de capacitação técnica na cadeia produtiva do bambu, desde o plantio de 120 moitas de bambus e instalação de galpão com equipamentos para produção de produtos e construção de estruturas. Para essas ações iniciais, foram necessários recursos financeiros obtidos através de editais, concursos, além da constituição de uma rede de contatos. A partir da coleta de dados em pesquisa bibliográfica, documental e aplicações de entrevistas semiestruturada, este estudo de caso busca revelar o processo desenvolvido nesta extensão universitária em seus onze anos de existência. A organização das informações permitiu uma análise do histórico, dos avanços obtidos e os pontos a aprimorar nesta relação de troca entre o grupo Taquara e os associados da Viverde.

Palavras chave: design - design social - extensão universitária - bambu - vulnerabilidade Social.

[Resumos em espanhol e inglês nas páginas 146-147]

(1) Doutorando no PPG em Design/FAAC/UNESP, Bauru, São Paulo, Brasil e Mestre (2016) PPG em Design/FAAC/UNESP, Bauru, São Paulo, Brasil, bacharel em Design pela FAAC/ UNESP, Bauru. Pesquisador no Laboratório de pesquisa e experimentação em bambu Processamento da madeira e bambu processamento da madeira e materiais compostos.

(2) Doutoranda no PPG em Design/FAAC/UNESP, Bauru, São Paulo, Brasil e Mestre (2017) PPG em Design/FAAC/UNESP, Bauru, São Paulo, Brasil. Graduada em licenciatura em educação artística pelo Centro Universitário Belas Artes de São Paulo. Pesquisadora 
no Laboratório de pesquisa e experimentação em bambu - Processamento da madeira e bambu processamento da madeira e materiais compostos. É sócia fundadora e coordenadora de projetos do Instituto Botucatu.

(3) Livre-docente pela UNESP (2012), Bauru, São Paulo, Brasil; Pela mesma instituição, campus de Botucatu, São Paulo, é doutor em Agronomia (Irrigação e Drenagem - 1997) e mestre em Agronomia (Irrigação e Drenagem - 1992); graduação em Engenharia Agrícola pela UNICAMP (1982), Campinas, São Paulo; especialização em Irrigação e Drenagem pela UFV (1989), Viçosa, Minas Gerais; e especialização em bambu no “2001' Tcdc International Training Course On Bamboo" pelo CBRC - China National Bamboo Research Center (Hangzhou-China). Atualmente é professor adjunto e livre docente em Design e Construção com Bambu na UNESP, campus de Bauru. Docente do curso de Engenharia Mecânica e coordenador do Laboratório de Pesquisa e Experimentação em Bambu.

\section{Introdução}

Um assentamento rural representa a etapa de conquista na luta pela posse de uma terra e resulta de esforços coletivos de um movimento social baseado em relações solidárias. Ainda assim permanecem em vulnerabilidade social, visto que esta não se restringe à condição econômica, mas se trata da desigualdade de acesso aos direitos de cidadania. Em processos colaborativos de intervenção social, estudantes de design podem desenvolver instrumentos e habilidades para a transformação social ao se relacionarem com as populações vulneráveis. Este foi o propósito do contato entre o assentamento rural Horto Aimorés e a extensão universitária do Projeto Bambu da Universidade Estadual Paulista (UNESP), campus de Bauru, realizada pelo grupo Taquara, composto por alunos da mesma instituição de ensino superior.

A extensão universitária foi iniciada em 2008 com a transferência de conhecimentos de forma participativa, adequada às necessidades dos assentados. As atividades realizadas consistiram, inicialmente, em capacitação técnica na cadeia produtiva abrangendo o plantio, manejo, colheita dos colmos, tratamento preventivo, secagem, até o processamento para obtenção de ripas laminadas e confecção de produtos artesanais em bambu in natura e laminado colado. Para estas ações iniciais e outras mais, foram necessários recursos financeiros obtidos através de prêmios e editais públicos e privados.

O estudo de caso desta extensão foi realizado com investigação em bibliografia, entrevistas semiestruturadas e pesquisa em documentos. A partir do histórico levantado observam-se os avanços obtidos e os pontos a aprimorar, visando a continuidade no processo de troca entre os envolvidos. Deste projeto surgem questões relacionadas ao design e ao sistema de implantação do projeto de extensão. 


\section{Extensão Universitária em Assentamento Rural de Agricultura Familiar}

Há mais de 20 anos, cerca de 500 mil famílias foram assentadas no território brasileiro, graças ao êxito de procedimentos estratégicos de disputa fundiária que, sustentadas pelas forças organizadas da população, vem requerer a efetivação de projetos de reforma agrária e assentamentos rurais (Norder, 2004). De acordo com este autor, um dos maiores desafios para os assentamentos rurais e para a agricultura familiar no país é responder à concorrência no mercado brasileiro de agricultura. Em explicação ou mesmo autor apontou que o projeto de modernização aplicado no modelo de desenvolvimento rural nacional, que se baseia em altos investimentos e baixa mão de obra, possui uma configuração que não favorece a produção de núcleo familiar.

Segundo Mior (2000), a agricultura familiar é uma estratégia de desenvolvimento rural que desde os anos de 1990 tem se fortalecido no Brasil. Para a melhoria das condições de vida dessa população no campo, estudos abordam a questão do conjunto de diversas estratégias sociais e econômicas a serem adotadas que não se caracterizam especificamente como atividades rurais agrícolas. Inclui-se entre outras fontes de recursos e meios para gerar renda o artesanato, o comércio, o turismo rural e o trabalho assalariado fora do meio rural (Norder, 2004).

A competência das atividades artesanais na geração de renda representa uma renovação "do ambiente educacional no meio rural" quanto mais elas incorporem materiais obtidos no território para a produção de produtos elaborados com técnicas tradicionais ou saberes adquiridos dentro de seu meio (Abramovay, 2000, p. 12). O autor afirmou que o Brasil carece de estudos orientados à educação no meio rural de visão territorial. No que concerne às políticas públicas, o mesmo autor apontou que, enquanto se faz o direcionamento apenas para profissionalização técnica com cursos profissionais dos agricultores, sem a perspectiva de buscar oportunidades locais de desenvolvimento, a condição dos habitantes do meio rural, especialmente para os jovens, não ultrapassará ao nível de mão-de-obra para serviços externos ao seu meio.

Em uma nova perspectiva do meio rural com iniciativas inovadoras, a sociedade local pode considera-los como "potenciais protagonistas de um pacto territorial na configuração de um novo ambiente a partir de referências do conhecimento no meio rural" (Abramovay, 2000, p. 10). Nesse sentido, é preciso uma contínua ação coletiva de organizações sociais, cujo papel dos movimentos sociais, profissionais e extensionistas é fundamental. $\mathrm{O}$ apoio das universidades no interior do país pode contribuir na constituição de uma nova visão e significado do meio rural (Abramovay, 2000).

\section{Design, humanismo e vulnerabilidade social}

O design é um conjunto de ferramentas que permite o uso de técnicas, formas de organização e planejamento, conceitos estéticos e funcionais, que podem ser aplicados, a partir desse pensamento sistêmico, no local de trabalho de uma comunidade. Os questionamentos surgem inicialmente, e demandam dos designers, uma observação e uma escuta 
mais apurada para elencar as necessidades mais urgentes a serem atendidas e relacionadas, entre outras, à projeção de um trabalho, à melhoria de uma produção ou do espaço para se realizar o trabalho. Com esta abordagem espera-se dos designers ou dos extensionistas uma percepção e sensibilidade frente complexidades de um grupo social. Com base na compreensão sistemática das necessidades comuns da comunidade, ou seja, dificuldades de recursos, hábitos, crenças, relações pessoais e também entre diversas questões externas à comunidade, apresentam-se as ferramentas do design para visualização das ideias do projeto, intrinsecamente pertinentes aos pontos levantados acima.

O design social orientado para o contexto do meio rural de um assentamento precisa levar em conta a questão das identidades fragmentadas, configurada por um grupo de pessoas de origens diversas. Considerando-se que a perspectiva da reconstituição física de um espaço rural, cultural e social é condição comum entre elas. Neste cenário, o sentido de pertencimento e o protagonismo local podem ser trabalhados na construção da identidade social e cultural da comunidade daquela localidade, com apoio de projetos extensionistas das universidades, de profissionais de diversas áreas, políticas públicas e a sociedade civil. Dependendo dos objetivos esperados destes trabalhos com essa população, inúmeros critérios para atuação dos designers ou extensionistas com o social podem ser considerados. O próprio termo design social não é implícito no discurso de alguns autores, contudo identifica-se o fazer "design no social" pelas formas das relações desse trabalho com a sociedade que se utilizam de critérios com bases humanistas, políticas e de sustentabilidade. Assim propôs Manzini (2009), ao reconhecer a ideia da formação de uma sociedade sustentável, em que pessoas e comunidades tem acesso igualitário aos bens e serviços com a liberdade de escolher o que querem ser e fazer de forma sustentável, respeitando o meio ambiente e os limites da resiliência dos ecossistemas. Com base nesta definição, o autor atribuiu ao design o papel para facilitar o processo de aprendizagem social para a construção de uma sociedade sustentável, através de pactos de inovações sociais e tecnológicas e na reorientação de causas emergentes para a sustentabilidade. Essa visão é endossada pelo "humanismo projetual" que Bonsiepe (2013, p. 21) apontou como meio à redução de hegemonias em que as ações projetuais são capazes de interpretar, a partir de uma consciência crítica, necessidades de grupos excluídos e de propor processos emancipatórios através do design na forma de artefatos ou serviços.

Löbach (2011), também se ocupou de observar o ser humano para entender o que o diferencia sendo parte de um sistema social complexo das relações humanas com os objetos. Nesta perspectiva inferiu que "nem todas as necessidades humanas são satisfeitas com objetos" (Löbach, 2011, p. 31). Diante tal afirmação, indaga-se no contexto do mundo atual sobre o consenso ou conflito dentre as opções que se apresentam ao design na resolução de problemas frente a um grupo social excluído da sociedade. Respondendo a isso no momento contemporâneo, Walker (2017, p. 49) propôs repensar o caminho para o design de forma que valorize uma perspectiva mais ampla, capaz de reavaliar, reinterpretar e recuperar questões que ficaram submersas na corrida para o progresso "desenvolvimentista”. O autor destacou que, com base em processos de criação, pode-se contribuir para a construção de uma comunidade, recuperação de ecossistemas e estimular a noção de identidade e unidade. Também enfatizou que o artesanato se enquadra nessa categoria, 
sendo um trabalho possível de ser realizado por esforços individuais ou coletivos e não necessariamente por designers qualificados (Walker, 2017).

Tomando o cenário social do país como plataforma de ação, observa-se que é imprescindível fazer um balanço sobre as abordagens de design social assumidas até hoje. Oportunamente Silva (2018) analisou criticamente as condicionantes destas abordagens ao observar o trabalho de designers ligados às questões sociais. Para a autora a vulnerabilidade social não se restringe a condição econômica ou ao critério da faixa de renda, nela também reside a desigualdade no acesso aos direitos fundamentais pelos diferentes grupos sociais. Num sentido mais detalhado, a mesma autora analisou criticamente a falta de políticas de emancipação de grupos sociais para superação da vulnerabilidade socioeconômica, observando trabalhos feitos por designers ligados às questões sociais e os classificou em quatro vertentes: assistencialista, humanista, culturalista e crítica. A autora declarou que as vertentes assistencialista, humanista e culturalista tratam os usuários corretamente, mas reiteram suas condições de pobreza por terem como método o atendimento a resultados imediatos. Continuando, a autora descreveu a vertente do design crítico como focada na autogestão estimulando-se o potencial emancipatório do grupo social, cuja regra é a autonomia coletiva, permitindo aos usuários a participação nas decisões e elaboração das normas de produção, e aos designers a elaboração de instrumentos adequados às necessidades.

\section{Objetivo}

Revelar o processo desenvolvido na extensão universitária do Projeto Bambu com o assentamento rural Horto de Aimorés.

\section{Os Procedimentos Abordados para o Resgate Histórico}

Para a coleta de informações foram feitas pesquisa bibliográfica, investigação de documentos e aplicações de entrevistas semiestruturadas. No levantamento as informações foram organizadas em tópicos que resgatam o histórico da extensão universitária realizada no Projeto Bambu pelos alunos do Taquara junto a um grupo de famílias do assentamento rural Horto de Aimorés. A análise dos tópicos revela os processos de: aproximação do Projeto Bambu com o assentamento; formação do grupo de alunos Taquara; formalização da Associação Agroecológica Viverde; atuação do empreendimento Viverde.

Na pesquisa bibliográfica fez-se a leitura de artigos publicados em periódicos e capítulos de livros que tivessem como tema central o trabalho extensionista desenvolvido no Projeto Bambu. Na investigação documental foram considerados os relatórios de projetos de pesquisas realizados na extensão universitária do Projeto Bambu. As entrevistas semiestruturadas foram aplicadas com três artesãos ativos na Viverde, um ex-aluno protagonista na fundação do grupo Taquara e o professor coordenador do Projeto Bambu. 


\section{Resultados e Discussões}

O resgate histórico da extensão universitária do Projeto Bambu trouxe à tona o caminho percorrido por um grupo de alunos, denominado Taquara, em conjunto de moradores do assentamento rural Horto de Aimorés, articulados inicialmente em grupo agroecológico Viverde. Em um primeiro momento foram promovidas atividades práticas no campo, buscando uma conexão com a realidade dos envolvidos enquanto agricultores, uma vez que o bambu poderia lhes servir como recurso local capaz de atender as demandas em seus lotes. A partir deste convívio estabeleceu-se uma abertura para expansão das vivências de campo realizadas em área agrícola, para atividades semanais em oficina do Laboratório de Experimentação com Bambu. Neste momento o projeto de extensão passava a nutrir as expectativas dos envolvidos na possibilidade da geração de renda com a comercialização de produtos feitos em bambu e prestação de serviços especializados no cultivo e aplicação desta matéria prima.

O nascimento do grupo Taquara protagonizou o delineamento das atividades extensionistas desenvolvidas com os assentados quando estes passaram a frequentar o laboratório. Com abordagem em design social os alunos realizavam atividades semanais com os agricultores na oficina, explorando os conhecimentos da cadeia produtiva do bambu e do processo de design na geração de novos produtos. As conquistas na captação de recursos materiais e financeiro foram imprescindíveis à estruturação, à manutenção e à expansão do projeto de extensão universitária. Para apresentar o panorama investigado, formulouse um infográfico que destaca os acontecimentos importantes na trajetória percorrida, e que organiza tais eventos em momentos maiores, elaborados a partir da análise das informações coletadas. A Figura 1 mostra o infográfico deste resgate histórico.

Os acontecimentos apontados no infográfico tiveram desdobramentos que representam a totalidade dos episódios vividos nessa extensão universitária. A apresentação detalhada dos momentos que englobam os marcos importantes e o que deles resultaram é feita na continuidade.

\section{A extensão universitária do Projeto Bambu}

\section{A organização do grupo agroecológico Viverde}

Em meio ao processo de regularização da posse de terra a Incubadora de Cooperativas Populares (INCOP) da UNESP, campus de Bauru, iniciou o seu trabalho com um grupo de famílias, até então acampadas. Por meio de um Diagnóstico Rural Participativo (DRP) a incubadora buscou reconhecer o contexto em que estavam imersos os sujeitos acampados e então atuar sob a realidade verificada. Como as famílias envolvidas já desenvolviam agricultura orgânica, seja pela bagagem de vida ou pelos aprendizados obtidos nos cursos do Serviço Nacional de Aprendizagem Rural (SENAR), a incubadora se propôs a auxiliar no processo de comercialização das produções destes agricultores, visando a geração de 


\section{RESHATE HISTÓRILO}

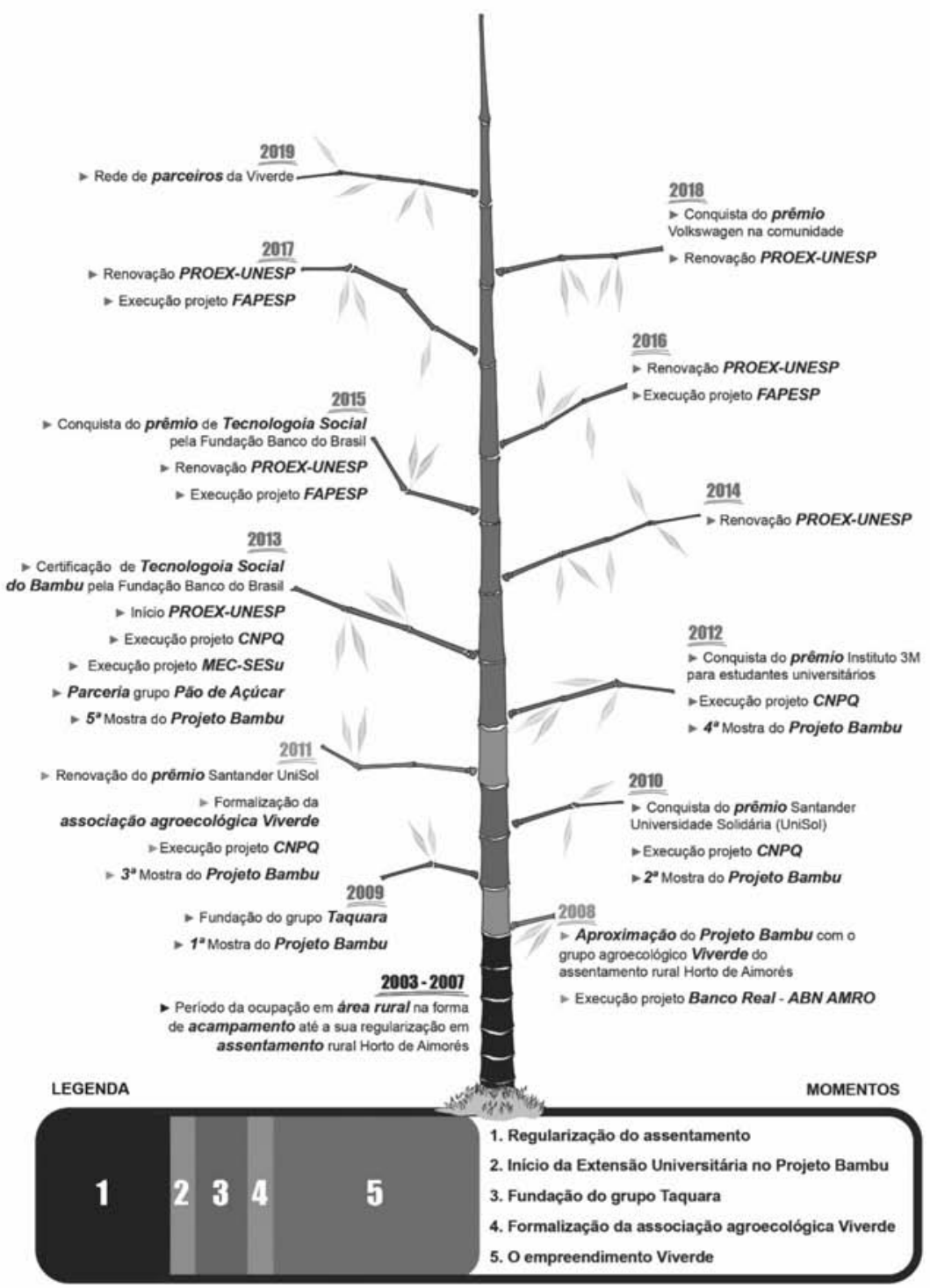

Figura 1. Infográfico dos momentos e acontecimentos ao longo dos anos. 
renda. Assim nascia o grupo agroecológico Viverde e sua relação com a universidade. Em meio a este trabalho, a incubadora fez a ponte de aproximação dos assentados com o Projeto Bambu em 2008, sob a proposta de serem produzidos caixotes em bambu. Este produto atenderia a demanda que surgiu com as vendas de orgânicos pelo grupo Viverde, devido ao transporte e exposição dos produtos.

\section{O início da extensão no Projeto Bambu}

O Projeto Bambu foi concebido pelo professor Dr. Marco Antonio dos Reis Pereira em 1990 e permanece em atividade sob sua coordenação. Fazem parte da sua infraestrutura o Laboratório de Experimentação com Bambu e a área agrícola. Enquanto na área de campo têm-se, desde 1998, o cultivo de espécies de bambus em 1,5 hectares e a infraestrutura para os tratamentos preservativos e estocagem de colmos, no laboratório encontram-se as ferramentas, equipamentos e maquinários, destinados a transformação do material em produtos diversos.

O Projeto Bambu abrange toda uma cadeia produtiva do bambu, envolvendo a identificação de espécies de bambus, o manejo da cultura, a colheita de colmos, a confecção e plantio de mudas, as aplicações de tratamentos preservativos, a estocagem, secagem e beneficiamento do material, a confecção de produtos artesanais e processados e a construção de estruturas.

O início da extensão universitária fez-se com a execução de um projeto financiado pelo banco Real - ABN AMRO. Para as investigações necessárias foi concedida bolsa de estudos, designada a um aluno de Desenho Industrial, com habilitação em Projeto de Produto. A primeira atividade foi na forma de palestra na gleba 1 da comunidade, em sua área comunitária de no 5 .

Na sequência deste primeiro contato, as atividades passaram a ser promovidas em formatos de oficinas práticas na área agrícola do Projeto Bambu, buscando capacitar os envolvidos nos conhecimentos necessários para a identificação de espécies, manejo, colheita, confecção e plantio de mudas, tratamentos e estocagem dos bambus. Uma vez inseridos na cultura do bambu, os agricultores passaram a vislumbrar no trabalho com esta matéria prima uma alternativa para a geração de renda.

\section{O grupo de alunos Taquara}

\section{A fundação do Taquara}

Em 2008, o bolsista do projeto de extensão motivou outros alunos do curso de Design da UNESP, campus de Bauru, a participarem das ações realizadas no Projeto Bambu. Diante a abertura cedida pelo coordenador do Projeto Bambu os alunos pleitearam a criação de um coletivo, fundado em 2009 e denominado Taquara, sendo composto por graduandos 
de Arquitetura e Urbanismo, Design de Produto e Design Gráfico. Em seu primeiro ano, o Taquara permitiu a consolidação do coletivo, a elaboração de um estatuto para a sua continuidade e a aplicação prática de teorias e conceitos junto as atividades extensionistas. Como desdobramento destes resultados alcançados, verifica-se a construção inicial de um conhecimento transdisciplinar.

A transdisciplinaridade fez-se possível no espaço das inter-relações geradas com as ações extensionistas, enquanto a equipe de alunos, técnicos e professores atuavam nos conhecimentos acadêmicos, os agricultores contribuíam com o pragmatismo cultivado em suas histórias de vida. A exemplo desta integração tem-se o resgate de técnicas tradicionais, como por exemplo o domínio na confecção de entramados por um dos membros do grupo Viverde, a articulação deste saber dentro da cadeia produtiva do bambu e sua disseminação por meio de oficinas para os demais envolvidos, assim como para o público externo. Em celebração e divulgação dos resultados alcançados no primeiro ano de Taquara, os alunos e o coordenador do Projeto Bambu criaram a "1a Mostra do Projeto Bambu", convidando o público da academia e da região de Bauru a visitarem o seu conteúdo. No espaço físico da exposição ocorria a interação do público com a ambientação, enquanto aconteciam, concomitantemente, oficinas na infraestrutura do Projeto Bambu sobre etapas da cadeia produtiva do bambu. Como resultado do trabalho coletivo entre Taquara e Viverde na realização das oficinas, pôde-se ao mesmo tempo expandir a disseminação dos conhecimentos da cadeia produtiva do bambu para o público interessado e aprofundar a integração dos alunos com os assentados.

A eficácia na divulgação da $1^{\text {a }}$ mostra fez do evento um sucesso de público, o que favoreceu o início da comercialização dos produtos artesanais e processados que o grupo Viverde já confeccionava. A prospecção da primeira comercialização foi sendo aprimorada ao longo de 2009, contando com a construção da identidade visual do grupo Viverde pelos alunos do Taquara e com a dedicação dos assentados nas atividades semanais realizadas na oficina do laboratório e no bambuzal da área agrícola.

\section{A estruturação e permanência do Taquara}

Em 2010 o projeto de extensão desenvolvido foi agraciado com o 12 Prêmio Santander Universidade Solidária (UniSol), financiando bolsas de estudos e a aquisição de materiais de consumo, ferramentas e maquinários. Para além do investimento financeiro conquistado, a equipe técnica da UniSol acompanhava constantemente o desenvolvimento das ações por meio de monitorias presenciais e avaliação de indicadores sociais, econômicos e ambientais. Os indicadores tomavam como referencial o contexto em que o assentamento se insere e as condições técnicas e humanas da equipe executora - alunos, técnicos e professores. Deu-se o título de marco zero à formulação dos indicadores em início de projeto, que ao ser acompanhado e atualizado ao longo do tempo, permitia a verificação detalhada dos progressos e retrocessos cometidos. Ao mesmo tempo em que ocorria as atividades extensionistas, os alunos do Taquara organizaram um processo seletivo para ampliar o coletivo. 
Neste ano também foi captado recurso financeiro junto ao Conselho Nacional de Desenvolvimento Científico e Tecnológico (CNPQ), concedido como bolsa de produtiva em pesquisa para implantação da Rede Bambu. Com duração de três anos, 2010-2013, esta pesquisa disponibilizou bolsa de estudos, contratação de serviços de terceiros e aquisição de materiais e ferramentas.

Com o desenvolvimento das ações extensionistas em auxílio da UniSol entendeu-se como primordial a expansão do trabalho para dentro da comunidade, buscando a sua difusão junto a outros moradores do local. Neste sentido, a capacitação realizada com o grupo Viverde passou a expectar que tais assentados pudessem, futuramente, reaplicar os conhecimentos adquiridos na implantação e consolidação da cadeia produtiva do bambu dentro da comunidade. Em análise das possíveis necessidades advindas com esta expansão local do projeto de extensão, verificou-se que as áreas dos conhecimentos que compunham o Taquara eram insuficientes para que as ações dessem o devido atendimento às complexas relações humanas. Assim, estabeleceu-se parceria com outros coletivos da mesma universidade, como a INCOP, composta por alunos de áreas diversas; o grupo Interage da Psicologia; a empresa júnior das Engenharias, a Pró-Jr; e grupo AGR das Relações Públicas. Dos resultados alcançados ressaltam-se as ações dentro da comunidade; o início da participação do grupo Viverde em feiras locais de artesanato; o cadastramento dos agricultores junto a Secretaria da Cultura como artesãos; a concessão de uma área comunitária do assentamento para uso do grupo Viverde; o plantio de 120 mudas de bambus na mesma área para futura autossuficiência em recurso material; a articulação inicial para uma proposta de projeto de um galpão, também neste local; a aquisição de diversos materiais, ferramentas, equipamentos e maquinários empregues na cadeia produtiva do bambu; a divulgação dos resultados da extensão universitária em eventos científicos e em programas regionais de rádio e televisão; a realização da $2^{\text {a }}$ Mostra do Projeto Bambu e a aprovação na continuidade do projeto de extensão em 2011 pelo $12^{\circ}$ Prêmio Santander Universidade Solidária.

\section{A formalização da Associação Agroecológica Viverde}

\section{O suporte fornecido pelo projeto de extensão}

Em função da renovação do apoio financeiro do banco Santander e assessoria da UniSol, durante o ano de 2011 foram continuadas as ações extensionistas com o grupo Viverde. Neste sentido, a qualificação dos artesãos nos conhecimentos da cadeia produtiva do bambu fez-se com o aprimoramento das técnicas já assimiladas e a exploração de novas. O fomento desta capacitação dos artesãos visava torna-los aptos na reaplicação dos conhecimentos adquiridos e necessários à implantação da cadeia produtiva do bambu dentro da comunidade, estimulando a sua expansão local. A Figura 2 mostra alguns dos produtos confeccionados pelos artesãos, concebidos em colaboração com os alunos do Taquara durante os trabalhos semanais na oficina do laboratório do Projeto Bambu. 


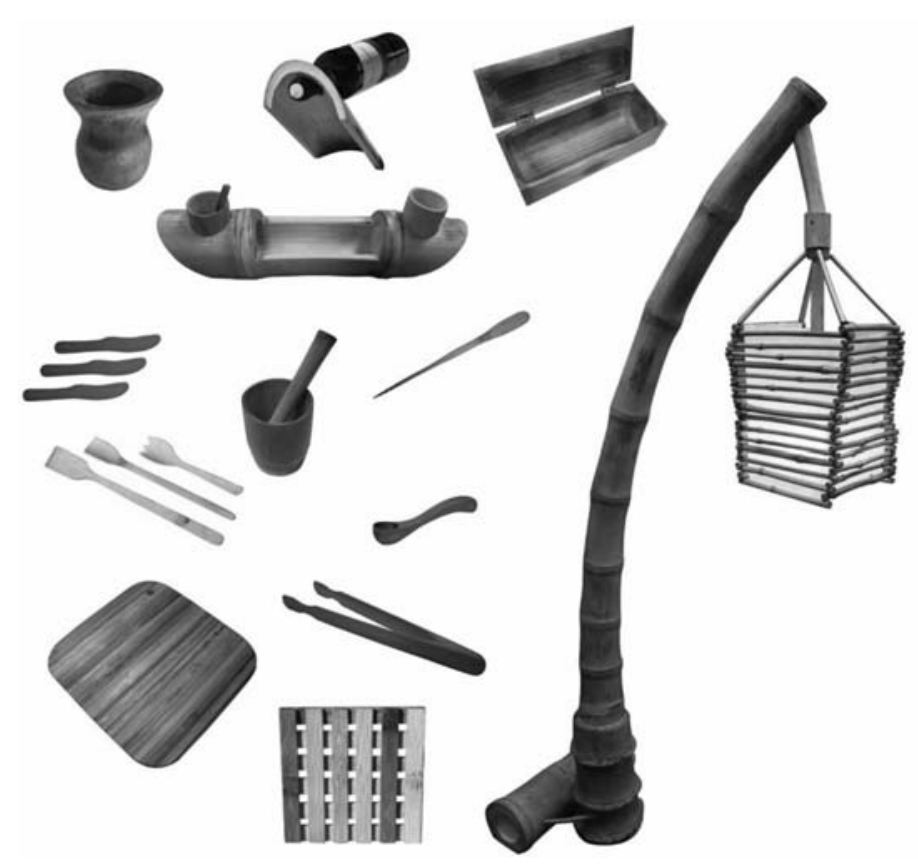

Figura 2. Produtos confeccionados pelos artesãos com colaboração do Taquara.

A troca de saberes entre alunos e artesãos também se estendeu à administração do empreendimento iniciado com a comercialização de produtos feitos em bambu. O auxílio prestado aos artesãos nesta gestão não era a nível de capacitação, pois o conhecimento demandado não era de domínio da equipe envolvida. Assim sendo, e mesmo sob esta adversidade, os alunos se empenharam com ajudas no controle da produção e do fluxo de caixa. A partir da experiência adquirida no ano anterior, o grupo Taquara se abriu para integrar as áreas da Engenharia de Produção e Relações Públicas. Essa composição buscava melhorar os processos de produção e comercialização do grupo Viverde, articular as atuações dentro da comunidade e ampliar a divulgação da extensão nas diversas mídias e eventos acadêmicos. Além de serem englobadas outras áreas do conhecimento, também foram estabelecidas novas parcerias. A constituição de uma rede de atores, numa soma em que distintos conhecimentos se transformaram em ações práticas, fez-se de modo dialógico e participativo com os artesãos.

Dentre as ações promovidas evidencia-se o direcionamento para suas ocorrências dentro da comunidade. Quanto aos seus conteúdos, vê-se uma abordagem para além do viés econômico da cadeia produtiva do bambu. Este formato de atividades se manteve ao longo dos anos da extensão, sendo desenvolvidas dinâmicas com os jovens e crianças da comu- 
nidade, abrangendo atividades educativas e socioculturais na forma de oficinas recreativas e sessões de cinema com o Cine Taquara. Na realização destas atividades, o envolvimento dos artesãos da Viverde estimulou que outros moradores participassem, criando e fomentando um grupo assíduo.

\section{O início da construção do galpão e a criação da associação}

Para viabilizar a construção de um galpão equipado com as ferramentas, equipamentos e maquinários já adquiridos, além dos recursos financeiros foram somadas doações por meio de parcerias. Dentre os parceiros, a prefeitura de Pederneiras terraplanou o local de construção do galpão e junto a Companhia Paulista de Força e Luz (CPFL) obteve-se a doação de postes de aroeira que serviram como pilares da cobertura.

Dos resultados alcançados em 2011, destaca-se a formalização da Associação Agroecológica Viverde. Ao longo de quase quatro anos, a participação e envolvimento dos assentados na extensão desenvolvida, lhes permitiram estruturar um empreendimento capaz de gerar renda a partir da cadeia produtiva do bambu. Neste processo também se fez possível a construção identitária dos assentados enquanto profissionais artesãos. O modelo de produção cultivado deu-se sob os preceitos de uma economia solidária, valorizando o trabalho coletivo e a remuneração compartilhada igualmente, além de um caixa de $20 \%$ para a associação. Os artesãos participaram como protagonistas nas escolhas que levaram a formalização da associação, optando pelo modelo associativo em função das ideologias que nutriam. Com auxílio de um contador, indicado pelos próprios artesãos por terem nele a confiança de outros projetos realizados no assentamento, fez-se a regularização da associação.

Ainda neste ano, os alunos do Taquara construíram um catálogo de produtos confeccionados pelos artesãos da Viverde, buscando ampliar a divulgação do empreendimento, como mostra a Figura 3.
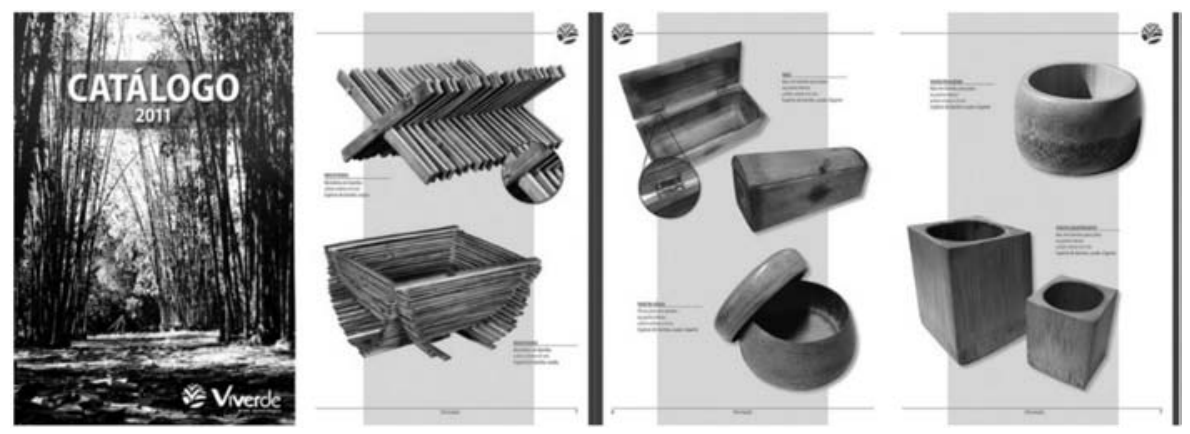

Figura 3. Catálogo impresso dos produtos confeccionados pela Viverde. 
Os canais digitais também foram adotados, sendo criado um blog do Taquara (http://taquaraunesp.blogspot.com/) voltado às atividades extensionistas e uma página da Viverde no Flickr (https://www.flickr.com/people/grupoviverde/). Para a Viverde ainda foi criado um perfil no Facebook (https://www.facebook.com/grupoviverde/).

\section{O empreendimento Viverde}

\section{A inauguração do galpão e sua ocupação pela Viverde}

Para que a cadeia produtiva do bambu fosse transferida para dentro da comunidade, bastava finalizar a construção do galpão, o que permitiria o trabalho da Viverde no local. Para isto, buscou-se captar recurso financeiro e assim elaborou-se uma proposta de projeto para o $4^{\circ}$ Prêmio Instituto $3 \mathrm{M}$ para Estudantes Universitários, sendo agraciado com o $1^{\circ}$ lugar. Com os recursos financeiros obtidos foram possíveis concluir o fechamento do galpão para ser oficialmente inaugurado e ocupado pela Viverde, e também conceder bolsas de estudos ao longo de 2012. Neste processo de finalização da obra também se buscou ajuda de parceiros, como as empresas Caetano e CGS Construção e Comércio que doaram todo o concreto usinado utilizado no contrapiso.

A abordagem do trabalho em canteiro de obras deu-se na forma de mutirões, que além de permitir uma maior velocidade na execução das ações, propiciava a troca de saberes entres os alunos e os assentados. Dessa forma os alunos contribuíam com seus conhecimentos técnicos e mão de obra, por sua vez os assentados colaboravam na execução prática e se beneficiavam com a especialização da ajuda.

\section{A continuidade da extensão e a implantação da cultura do bambu na comunidade}

Nos anos seguintes novos recursos financeiros foram buscados para a manutenção das atividades extensionistas. Em 2013 o grupo Taquara foi cadastrado na UNESP como projeto de extensão universitária, permitindo a sua participação nos editais da Pró-Reitoria de Extensão Universitária (PROEX) da instituição. A partir de então, anualmente o grupo tem obtido êxito na aprovação de bolsas de estudos e recurso financeiro para a compra de materiais de consumo. Ainda em 2013, a cadeia produtiva do bambu desenvolvida na extensão do Projeto Bambu foi certificada como uma Tecnologia Social, reconhecida pelo Banco de Tecnologias Sociais da Fundação Banco do Brasil. Neste mesmo período foi liberado o recurso conquistado em edital promovido pela Secretaria de Educação Superior (SESu) do Ministério da Educação (MEC), concedendo bolsa de estudos e compras de materiais e ferramentas.

Ainda sobre as parcerias, firmou-se contrato com o grupo Pão de Açúcar para participação da Viverde no programa "Caras do Brasil" com o fornecimento de talheres de bambus para dezenas de supermercados da rede. Como resultado dessa relação nos anos seguintes, 
teve-se um crescimento no fluxo de caixa da associação, agregando estabilidade na geração de renda pelos artesãos. Observa-se nesta diversificada rede de contatos a existência de diferentes perfis de parceiros, dos que atuam pontualmente, como ocorre com as doações, até aqueles que são cultivados, por prestarem ajudas especializadas. Em suma, a atuação em conjunto de uma rede de contatos é tão vital quão útil para ações extensionistas junto a populações vulneráveis.

Em 2015 a associação foi aprovada no Projeto Voluntariado da Fundação Banco do Brasil, captando recurso financeiro para a compra de maquinários destinados ao processamento do colmo de bambu, visando a confecção de placas de Bambu Laminado Colado (BLC). Assim a Viverde passou a explorar este material na confecção de seus produtos, agregando estética, valor comercial e novos conhecimentos com a técnica empregue. No mesmo ano conseguiu-se o aceite de financiamento pela Fundação de Amparo à Pesquisa do Estado de São Paulo (FAPESP) de um projeto de pesquisa proposto para ser realizado com a participação dos artesãos da Viverde. As investigações visavam o desenvolvimento de painéis modulares para fechamentos de ambientes. Ao se envolverem nas atividades desta pesquisa os artesãos puderam aprimorar os seus conhecimentos sobre construções com bambu. Mais recentemente, em 2018, a Viverde obteve a sua primeira conquista de forma independente a extensão, sendo contemplada no Concurso de Projetos Sociais - Volkswagen na Comunidade. Os recursos financeiros desta premiação foram destinados à compra de mais maquinários, inaugurando novas frentes de trabalho na cadeia produtiva do bambu, como a máquina de pellets que produz o biocombustível a partir dos resíduos de outras atividades da associação com o bambu.

Outros resultados obtidos com o desenvolvimento da extensão ao longo dos anos foram as celebrações ocorridas com as organizações da $3^{\mathrm{a}}$, $4^{\mathrm{a}}$ e $5^{\mathrm{a}}$ Mostra do Projeto Bambu, em 2011, 2012 e 2013, respectivamente; a continuidade da divulgação do projeto de extensão e do empreendimento Viverde, recorrendo as diversas mídias de comunicação; o desenvolvimento de estudos para eventos científicos e publicações acadêmicas; e a abertura do Taquara para as área das Artes, Biologia, Rádio e Televisão, Jornalismo e Engenharia Civil.

\section{A gestão do empreendimento Viverde}

Nos primeiro quatro anos de existência da extensão universitária o número de membros da Viverde reduziu. A distância entre a comunidade e a universidade somada ao tempo dedicado pelos assentados em seus lotes foram alguns dos fatores que contribuíram para esta diminuição de participantes. Depois de formalizada a associação esse cenário se estabilizou, mas mesmo assim, de 2011 a 2016, a entrada e saída de novos participantes fez-se constante. A partir de 2016 a Viverde passou a ser constituída por apenas um núcleo familiar, composto pelo presidente da associação com sua irmã e seu filho. Quando necessário, em função de altas demandas, faz-se a contratação da mão-de-obra de outros assentados. Atualmente, para auxiliar no processo de disseminação da Tecnologia Social do Bambu junto a outros moradores da comunidade, formou-se um novo grupo de colaboradores. Em conjunto dos artesãos, essa equipe também tem trabalhado para que ocorra uma maior abertura da associação para integração de novos associados. Os colaboradores são 
três doutorandos no Programa de Pós-Graduação em Design da UNESP, campus de Bauru, sendo que duas das pesquisas são alinhadas à comunidade e à associação. Ainda integra a equipe um doutor titulado na mesma área e instituição. Ao mesmo tempo busca-se reaproximar os alunos do Taquara com os artesãos da Viverde, pois com a instalação definitiva da associação na comunidade, as ações locais promovidas pelos alunos foram sendo reduzidas até não ocorrerem mais.

Finalmente, observa-se que as expectativas nutridas tanto com a expansão local da Tecnologia Social do bambu quanto com a consolidação do empreendimento Viverde, ainda não foram plenamente alcançadas. Não obstante, acredita-se que o processo desenvolvido ao longo do caminho percorrido nesta extensão universitária, faz-se um meio potencial para a continuidade das ações. Agora, localmente, dedicando-as à gestão do empreendimento Viverde, à inclusão de novos artesãos na associação, à disseminação da cultura do bambu junto à comunidade do assentamento.

\section{Conclusão}

Na extensão universitária promovida as experiências adquiridas possibilitaram um engajamento cívico dos alunos do Taquara e artesãos da Viverde, assim como lhes influenciaram no processo da construção identitária de suas profissões e empreendimento, como no caso da associação. A relação de troca concebida entre o grupo Taquara e os associados da Viverde demonstra uma lógica distinta do usual, focada somente na produção de novas mercadorias para agregação de valor pelas comunidades de artesãos.

A lógica da produção alcançada é resultante de um processo de design social articulado pela reflexão crítica sobre a realidade de vida dos sujeitos envolvidos e pela aplicação prática de planejamentos e ações inclusivas e cooperativas voltadas às realidades identificadas e investigadas. Dessa forma, pode-se afirmar que o conhecimento técnico trabalhado por meio do design social em atividades extensionistas contribui com a inovação social ao ampliar as oportunidades que garantam o desenvolvimento de processos e potencializem a autonomia de uma gestão futura dos associados.

A emancipação por meio da autogestão coletiva é um processo de construção do empoderamento dos artesãos envolvidos na extensão universitária. A autonomia pretendida requer que os participantes sejam qualificados nos conhecimentos técnicos abordados e conscientizados na importância de suas atuações diante as condicionantes que os diminuem em suas relações sociais, culturais, econômicas e políticas. Neste sentido, ressalta-se a importância das instituições de ensino superior enquanto agregadoras de conhecimentos de diversas áreas, fornecedoras de ensino, produtoras de pesquisa e possíveis fomentadoras da extensão universitária. Assim como há de ser dada a devida atenção aos parceiros da sociedade civil que possam vir a colaborar de formas diversas, como por exemplo os movimentos sociais, os técnicos e os especialistas. Somam-se nesta vital rede de parceiros os órgãos públicos e as empresas privadas com o fornecimento de recursos materiais e financeiro.

A implantação e desenvolvimento de um processo de design social que seja dialógico e participativo entre os participantes deve ser proativo e receptivo na busca e acolhimen- 
to de parceiros. Esta abertura, por sua vez, colabora no entendimento e atendimento das expectativas geradas com a extensão universitária, como também propicia a integração e transformação dos saberes técnicos, científicos e populares. A extrapolação transdisciplinar pode oferecer novas percepções do conjunto de ações realizadas, uma vez que na somatização dos conhecimentos envolvidos tem-se a representatividade dos moradores da comunidade e novos referenciais agregados pelo envolvimento de entidades e colaboradores.

\section{Bibliografia}

Abramovay, R. (2000). O capital social dos territórios: repensando o desenvolvimento rural. Economia Aplicada, 2(IV), 379-397.

Bonsiepe, G. (2011). Design, Cultura e Sociedade. São Paulo: Blucher.

Löbach, B. (2011). Design industrial: bases para a configuração dos produtos industriais (Vol. 1). São Paulo: Editora Edgard Blücher Ltda.

Manzini, E. (2009). Viewpoint New design Knowledge. Design Studies, 39(1), 4-12.

Mior, L. C. (2000). A agricultura familiar e o rural não agrícola como estratégia de desenvolvimento rural: algumas controvérsias do debate. In Instituto Federal Rio Grande do Norte. Rio de Janeiro: Sociedade Brasileira de Economia e Sociologia Rural.

Norder, L. A. C. (2004). Políticas de assentamento e localidade. Universidade de Wageningen, Wageningen.

Silva, V. Z. da. (2018, Maio). Os sentidos do design social. Vitruvius Arquitextos, 216(04). Recuperado de http://www.vitruvius.com.br/revistas/read/arquitextos/18.216/6991

Walker, S. (2017). Design for life: creating meaning in a distracted world (Vol. 1). London: Routledge.

Resumen: Un asentamiento rural representa una etapa de conquista en la lucha por la posesión de una tierra, resultado de esfuerzos colectivos de un movimiento social. Aun así, sus moradores encuentran dificultades durante la estructuración, permaneciendo socialmente vulnerables debido a una desigualdad de acceso a derechos ciudadanos. En este contexto, se estableció la relación entre los moradores del asentamiento rural Horto de Aimorés en Bauru y el proyecto de extensión universitaria Projeto Bambu. En el mismo período se formó la asociación agroecológica Viverde contando con el apoyo del grupo Taquara, formado por alumnos de las facultades de Diseño, Arquitectura e Ingeniería de la UNESP, en el campus de Bauru. Las actividades de extensión con base en el diseño social permitieron la profesionalización de los moradores del asentamiento como artesanos del bambú. Enfocadas en la generación de renta, se realizaron oficinas de capacitación técnica en la cadena de producción del bambú, desde la plantación de 120 mudas de bambú, junto con la construcción de un galpón con maquinaria para producción y construcción de estructuras y productos. Para estas acciones iniciales, fueron necesarios recursos financieros 
obtenidos a través de editales, concursos, además de la creación de una red de contactos. A partir de la colecta de datos de fuentes bibliográficas, documentales y entrevistas semiestructuradas, este estudio de caso busca revelar el proceso desarrollado en este proyecto de extensión universitaria en sus once años de existencia. La organización de la información permitió un análisis histórico de los avances obtenidos, así como de los puntos a mejorar en esta relación de intercambio entre el grupo Taquara y los asociados de Viverde.

Palabras clave: diseño - diseño social - extensión universitaria - bambú - vulnerabilidad social.

Abstract: A rural settlement means a landmark achievement phase because of hard work of social movement efforts in the struggle for possession of a land. Nevertheless, its residents find several difficulties to their structuring and remain in social vulnerability, due to the inequality of access to the rights of citizenship. Under these circumstances, was therefore established a partnership between residents of the Horto de Aimorés rural settlement in Bauru and the university extension of the Projeto Bambu. In the same period, a group of residents formed the Associação Agroecológica Viverde with support from the Grupo Taquara composed of students from the Faculties of Design, Architecture and Engineering of UNESP, Bauru campus. Extension activities with social design-based approach allowed residents for qualification as bamboo artisans. They were benefited by capacitating in technical training workshops held in the bamboo production chain, from the planting of 120 bamboo plants and installation of workshop facilities for product production and construction of structures with focus on social inclusion and income generation. Network opportunities and financial support from competitions allocated the necessary resources in order to initiate required actions. Data collection drew extensively sources of information from bibliographic research, document search and semi-structured interviews. This case study shall reveal the process developed in this university extension in its eleven years of existence. This organisation of the information provided an analysis of the history and the progress made within this contribution of sharing and exchanging experiences between the group Taquara and the associates of Viverde.

Keywords: design - social design - university extension - bamboo - social vulnerability.

[Resúmenes en inglés y portugués en la página ] 